\title{
Reasoning Ability in Science of Secondary School Students In Relation To Some Personal Variables
}

\author{
Savita Mishra
}

\begin{abstract}
Science education has become a priority subject area in the present generations and it has a worldwide significance. It has brought about revolutionary changes in every walk of our lives. It has been a compulsory subject from the primary to the higher levels in all over the world. Therefore the priority research area in the school education system has been research in science education. The present study is a sincere attempt of the investigator to assess reasoning ability in science of secondary school students in relation to some personal variables. Reasoning ability in science according to Joshi and Mahapatra (1994) has been categorized as follows; inductive reasoning, deductive reasoning, analogy as reasoning, abstract reasoning, axiomatic reasoning, eclectic reasoning, syllogistic reasoning and classification as reasoning. The mental exercise or the power of mind to deduce inferences from premises concerning all information of sciences to argue, to examine, to think out, to bring by rationale is called scientific reasoning. Scientific reasoning refers to "the mental exercise of inferring relationships among facts and phenomena having scientific basis, evaluating evidences and coming to a conclusion", (Joshi and Mahapatra, 1994). It may also called the reasoning ability in science. Ghosh (1989) conducted a study on development of scientific reasoning, scientific attitudes of students and found that development of such thinking depended upon the student's perception of learning science. The students' reasoning ability in science was assessed through the administration of Joshi and Mahapatra's scale (1994) over a sample of 100 boys and girls in 10 schools of Gangtok city in Sikkim state of India selected on simple random basis, and the results were extrapolated through projective technique based on a normative study design.. The personal variables here were referred to age, sex, type of subjects preferred, achievement, intelligence, educational aspiration, attitude towards science and parental education, occupation, income and facilities available in schools for science teaching. The study revealed significant differences in reasoning ability in science in relation to age, sex, type of subjects preferred. Among the psycho social variables, significant differences were observed in reasoning ability in science of students having high and low level of achievement, intelligence, educational aspiration, attitude towards science and socioeconomic status. Significant relationship existed in reasoning ability in science and intelligence, achievement, educational aspiration and attitude towards science.
\end{abstract}

\section{INTRODUCTION}

The progress, welfare and prosperity of a nation depend on a rapid, planned and sustained growth in the quality and extent of education and research in the science and technology. Thus, science has become a priority area in education both at the compulsory as well as at the level of specialization. Science and technology have opened the doors to the world of new thought and meaningful action. Science has brought about revolutionary changes in every walk of our life. Its impact is visible everywhere and in every aspect our existence, i.e. vocational, social, economic, political and cultural. We solely depend on science for domestic amenities, industrial production, communication, defense, medicine, agriculture, transport and so many other matters. So in each and every country special attention is given for the development of science. Most of the countries which popularized science among the adolescents have become modern and advanced and thus influenced the entire universe as compared to those which do not, or have lately introduced science in their system of education. Anyway, the people possessing positive attitude towards science get the benefits of science much as compared to those who lacked it.

Science, more than any other subject in the traditional school curriculum, has been closely associated with the economic and the social development of our society. Science education offers a knowledge base and a way of knowing which can be applied for effective solution of human environmental problems and to industrial development, Science Education enlightens the young generation in the following areas of knowledge.

$>$ Knowledge of science for healthy living - personal as well as social.

$>$ Knowledge of science for agriculture

$>$ Knowledge of science of ecological balance

$>$ Knowledge of science nutrition

$>$ Knowledge of science for clean environment and it's protection 
$>$ Knowledge of science for job requirement.

In the context of science, reasoning historically referred to formal reasoning characterized by rules of logic and mathematics. The formal processes of deduction or induction lead thinkers to necessary conclusions and positivist philosophers of science argued that these processes distinguish the scientific enterprise from other ways of knowing the world (Curd \& Cover, 1998). Kuhn (1993) challenged the significance of formal reasoning in science by proposing a novel model of scientific change and progress. Kuhn (1993) disputed the purported rationality of scientific theory change and the perpetual accretion of scientific knowledge. He described episodes of theory change as tumultuous periods during which scientists' judge competing theories using a variety of criteria including social influences. An enduring theory rises to prominence through a process more reminiscent of political revolutions than episodes of formal reasoning. Kuhn's work directed attention to the fact that although formal reasoning may contribute to scientific discovery, it is not the only vehicle for producing progress. Although the results of science may be presented in the language of formal reasoning and logic, the results themselves originate through informal reasoning (Tweney, 1991). Unlike scientific investigations, the premises of formal reasoning are fixed and unchanging and conclusions are necessary derivatives. In informal reasoning, on the other than, premises can change as additional information becomes available, and conclusions are not self evident (Lawwon,1982). Informal reasoning involves the generation and evaluation of positions in response to complex issues that lack clear-cut solutions. Thinkers are engaged in informal reasoning as they ponder causes and consequences, pros and cons, and positions and alternatives. (Stuessy,1984).Fleming (1986) provided an illustrative description in the following: "Informal reasoning assumes importance when information is less accessible, or when the problems are more open ended, debatable, complex, or ill-structured, and especially when the issue requires that the individual build an argument to support a claim". Post positivist accounts of science describe the enterprise as a multifaceted set of disciplines which employ informal reasoning (Tweney, 1991). Socio-scientific issues are ideal candidates for the application of informal reasoning ( Kuhn, 1993). By definition, they are complex, open-ended, often contentious dilemmas, with no definite answers in response to socio scientific dilemmas; valid, yet opposing, arguments can be constructed from multiple perspectives. Just as scientists employ informal reasoning to gain in sighting on the natural world, ordinary citizens rely on informal reasoning to bring clarify to the controversial decisions they face. The citizens of a democratic society built upon science and technology are constantly presented with socio-scientific issues, and the processes of informal reasoning allow them to access these issues, formulate positions, and provide supporting evidence.

\section{Concept of Reasoning Ability in Science}

The term reasoning is originated from the term reason. The meaning of reason is to put data together and establish relation between them on the basis of rationale. Solving problem through reason is called reasoning. Good (1973) defined reasoning as "the development of the meaning and content of ideas through operating symbols constituting propositions so that, the propositions stand in serial order constituting argument or discussion. The meaning of reasoning according to Chamber's Dictionary: It is the power of mind of drawing conclusion and determining right and truth. The exercise of that power: sanity: conformity to what is fairly to be accepted or called for. To exercise the faculty of reason, to deduce inference from premises, to argue, to examine, to think out, to set forth logically, to bring by rational. In this way reasoning is a mental process to think out, to set forth logically, to bring conclusion on the basis of rationales. Reasoning ability in science according to Joshi and Mahapatra (1994) has been categorized as follows; inductive reasoning, deductive reasoning, analogy as reasoning, abstract reasoning, axiomatic reasoning, eclectic reasoning, syllogistic reasoning and classification as reasoning. The mental exercise or the power of mind to deduce inferences from premises concerning all information of sciences to argue, to examine, to think out, to bring by rationale is called scientific reasoning. Scientific reasoning refers to "the mental exercise of inferring relationships among facts and phenomena having scientific basis, evaluating evidences and coming to a conclusion",( Joshi and Mahapatra,1994). It may also called the reasoning ability in science. Ghose (1989) conducted a study on development of scientific reasoning, scientific attitudes of students and found that development of such thinking depended upon the student's perception of learning science.

Education in the field of science occupies an important place in order to create an enlightened citizenry having appropriate power of mental functioning and reasoning. Science teaching in the classroom situations in the present generation is aimed at mainly, development of scientific temperament, scientific creativity, and attitude towards science. Hence the curricula have undergone drastic change. Development of scientific reasoning in student will go a long way in accelerating them with the present day explosion of knowledge in science and technology. Hence the school education gives much importance to science teaching. Investigation in respect of inculcating scientific reasoning and attitude towards science in students are of prime importance. Considering this the present study is undertaken to investigate whether the secondary school students are getting knowledge in science theoretically or developing reasoning in them to apply and solve new situations that they may infant in their lives. Review of studies presented above show the importance of reasoning ability in science 
and some personal variables. Therefore, the problem may be stated as "Reasoning Ability in Science of secondary school students in relation to some personal variables."

\section{Objectives Of The Study}

The following were the objectives of the study;

1. To categorize different categories of students in reasoning and find out the proportion variance of students in different types of reasoning.

2. To assess reasoning ability in science of secondary school students in relation to personal variables of sex, locale, type of subjects preferred, achievement, educational aspiration, intelligence, attitude towards science, facilities for science teaching, socio economic status, parents educational background, occupation and monthly income.

3. To determine relationship between reasoning ability in science and other variables of achievement, educational aspiration, attitude towards science and intelligence.

\section{Hypotheses of the Study}

The following hypotheses were formulated in accordance with the objectives stated above. They have been expressed in null form for ease of verification.

$\mathrm{HO}_{1}$ : There does not exist significant difference in the level of reasoning ability in science displayed by the secondary school students.

$\mathrm{HO}_{2}$ : There does not exist significant difference in reasoning ability in science of secondary school students due to sex variation.

$\mathrm{HO}_{3}$ : There does not exist any significant difference in reasoning ability in science of secondary schools students due to locale variations.

$\mathrm{HO}_{4}$ : Reasoning ability in science is not significantly different in students preferring different science subjects like physics, chemistry, mathematics and biology.

$\mathrm{HO}_{5}$ : High and low level achievement variation wise secondary school students do not exhibit significant difference in their reasoning ability in science.

$\mathrm{HO}_{6}$ : There does not exist significant difference in secondary school students in reasoning ability in science in relation to their educational aspiration variation.

$\mathrm{HO}_{7}$ : There does not exist significant difference in reasoning ability in science of secondary school students in relation to intelligence and attitude towards science variations.

$\mathrm{HO}_{8}$ : The mean scores of secondary school students' reasoning ability in science are not significantly different in students with high and low level of parental education.

$\mathrm{HO}_{9}$ : There does not exist significant difference in secondary school students' reasoning ability in science with regard to parental occupation variation.

$\mathrm{HO}_{10}$ : The mean scores of secondary school students' reasoning ability in science are not significantly different with regard to their family's monthly income.

$\mathrm{HO}_{11}$ : There does not exist significant difference in secondary school students' reasoning ability in science in relation to facilities for science teaching.

$\mathrm{HO}_{12}$ : There does not exist significant relationship between reasoning ability in science and educational aspiration, academic achievement, attitude towards science and intelligence.

\section{Scope and Delimitations of the study}

Scope of the study was to assess reasoning ability in science of 100 students of class IX of ten secondary schools of Gangtok, Sikkim selected on simple random basis, through projective technique.

The Method Of Study: A normative survey study design was adopted for this study.

The Sample: A representative sample of 100 students, 50 boys and 50 girls of class $1 X$ were selected in a simple random basis drawn from ten different schools of Gangtok, Sikkim. From each of the school 10 students were randomly picked up who showed their interest and willingness to participate in the study. As such 50 boys and 50 girls were selected as sample for the investigation.

Tools used: The following tools were used for collection of data.

1. A personal data blank of the respondents developed by the investigators for collection of personal information like age, sex, school, management, school type, parental education, occupation, income and achievement marks. 
2. The tool was used for the conduct of study was Reasoning Ability in Science of Joshi and Mahapatra (1994). It consisted of five components (Analogical, Classification, Eclectic, Inductive, Deductive) and 30 test items. The test retest reliability of test was 0.76 and Concurrent validity co-efficient was 0.4 .

3. Grewal's science attitude scale (1990) was adopted to measure attitude towards science.

4. Educational aspiration scale of Majumdar (2004) was adopted for the assessment of educational aspiration of the students.

5. Jalota's test of intelligence (1951) was adopted for studying the level of intelligence.

\section{Techniques of data analysis}

For finding out significant difference in the level of students' reasoning ability in science the ' $t$ ' ratios were calculated as appropriate for the cases. Coefficient of correlation was calculated for establishing relationship between reasoning ability in science and other variables of achievement, educational aspiration, attitude towards science and intelligence.

\section{Results and Discussions}

The data were analyzed through descriptive as well as inferential statistics. The normality of distribution was studied through calculation of mean, median, standard deviation and percentiles. It was observed that the skewness and kurtosis of the curve were -0.09 and 0.22 respectively indicating slightly negatively skewed and the peakness of the curve indicated leptokurtic nature.

The classification of the sample was done taking $\mathrm{Q}_{3}$ and $\mathrm{Q}_{1}$ as cut off points and out of 100,15 were having highly reasoning ability in science, 62 average level and 23 were at the low level of reasoning ability in science. This revealed the fact that the students didn't show reasoning ability in science in equal magnitude. Differences existed in them, so far as their reasoning ability in science was concerned. This difference in reasoning ability in science was then studied in relation to the variables taken in the investigation.

\section{Differential analysis on reasoning ability in science}

Discussion was made in respect of studying the significant difference in reasoning ability in science of secondary school students with regard to personal variables of age, sex, type of subjects favoured, achievement, educational aspiration, intelligence, attitude towards science, facilities for science teaching, parental educational background, occupation and income through ' $t$ ' ratio and the results were tested for significance at 0.05 level of significance.

\section{Reasoning ability in science and sex difference}

Sex wise difference was indicated by the boys and girls having the mean and SD scores boys 52.56 and 6.31 and girls 55.81 and 5.69 respectively and the ' $t$ ' ratio was found to be $2.70\left(t_{\text {for df }} 98\right.$ at $0.05=1.98$ ) which was significant. The sex difference in reasoning ability showed greater mean scores in case of girls which is in tune with the present day trend in academic achievement of girls in all the areas surpassing the boys.

\section{Reasoning ability in science and locale variation}

Locale wise variation was applied to determine the level of reasoning ability in science of secondary school students The mean and standard deviations of both rural and urban students were calculated which were found to be55.72,52.76 and 6.25, 5.74 respectively, showing greater reasoning ability in science in case of rural students. The test of significance of difference between the two yielded a' $t$ ' ratio of 2.55 which was significant at 0.05 level.

\section{Subject preference and reasoning ability in science}

In this case attempt was made to find out reasoning ability in science in order of subjects preference of the students. It was observed that students having preference for science (physics, chemistry and biology) and mathematics had greater mean score compared to the students showing preference in languages, social science and others. A comparison was made in the mean score of reasoning ability in science of the students through two groups of science (M-56.55, SD-5.27) and non-science (M-52.03, SD-6.39) and the difference was quite visible in case of science students, the ' $t$ ' ratio being 3.89 which was significant. Therefore the null hypothesis pertaining to subjects' preference was rejected.

\section{Reasoning ability in science and Achievement}

Achievement of secondary school students seemed to effect the reasoning ability in science as the ' $t$ ' ratio between high group and low group on academic achievement showed significant difference $(t=9.12)$. Therefore 
the null hypothesis stating that there does not exist significant difference in relation to high and low achievement groups of students was rejected.

\section{Reasoning ability in science and Educational Aspiration}

Educational aspiration as a variable was incorporated in the study to find out significant difference in reasoning ability in science of students of high and low educational aspiration. This also seemed to affect the reasoning ability in science of the students having high academic aspiration being significantly different from the reasoning ability in science of students having low academic aspiration, the 't' ratio being 2.85 which was significant at 0.01 level of significance.

\section{Reasoning ability in science and level of Intelligence}

The mean difference in reasoning ability in science scores of students of high and low level groups of intelligence was found to be significant, the ' $t$ ' ratio being 7.20. Mean score and standard deviation of high intelligence group on reasoning ability being 59.55 and 7.72 was distinctly different from the mean score of the low intelligent group on reasoning ability (M-48.89 and SD-5.67).It is quite natural that intelligent students pursue careers in science and therefore the result tended to show in that direction.

\section{Reasoning ability in science and Attitude towards science}

It was observed that the $t$ ratio (5.60) in case of reasoning ability in science and attitude towards science was significant. Thus the null hypothesis that there does not exist significant difference in reasoning ability in science of the students on relation to attitude towards science was rejected. The findings revealed that reasoning ability in science is related to attitude towards science.

\section{Reasoning ability in science and Facilities for science teaching}

Investigation was conducted in the view of finding out reasoning ability in science of students reading in schools with proper facilities like science labs, science clubs, qualified science teachers and availability of journals, periodicals and books in science in the school libraries. The students were categorized under two groups of schools having adequate facilities and schools having no facilities. The student's reasoning ability score in these two types of schools were compared and ' $t$ ' ratio was found to be 1.79 which was not significant. Such a type of result indicated that reasoning ability in science can be developed by one's personal feelings, open mindedness and own judgement but not by schools having facilities.

\section{Reasoning ability in science in relation to socio-economic status variation}

Socio economic status is a great contributor towards development of reasoning ability in science. In the survey, parent's educational background, occupation and income were three determining factors. The educational background of parents was dichotomized into level of literacy below and above graduation. The occupation and monthly income were also similarly dichotomized as more than 5000 rupees per month and less than 5000 rupees and high occupational ranks like doctors, engineers, administrative officers, company secretaries, professors, academician, and the so called elite groups compared to the clerical cadre, factory workers, shop owners etc. All the three taken together, the socio economic status yielded a significant ' $t$ ' ratio but did not show significant mean difference in occupation, only significant difference in respect of reasoning ability in science was observed in the students dichotomized under parental education and income group.

\section{Relationship Study}

Relationship between reasoning ability in science and achievement in science was calculated as per the independent variables by applying Pearson's Product moment method which was found to be 0.273 . The significance value of ' $r$ ' at 0.05 and 0.01 levels for 98 degrees of freedom is 0.195 and 0.254 respectively. Therefore, the null hypothesis that there does not exist significant relationship between reasoning ability in science and achievement was rejected. It was concluded that there existed significant relationship between reasoning ability in science and achievement of students. The co-efficient of correlations calculated between reasoning ability in science and intelligence of secondary school students subsample wise also were calculated. It was observed that there existed significant relationship between reasoning ability in science and intelligence, reasoning ability in science and attitude towards science and reasoning ability in science and educational aspiration which were $0.214,0.216$ and 0.198 respectively.

\section{Conclusion \& Implication}

From the study it was observed that reasoning skills in the students developed through the teaching of science. Because science is a such subject which induces power of mind to deduce influence to argue, to 
examine, to think out and to bring into light scientific reasoning. The study also revealed that students performance in analogical, abstract and deductive reasoning were more compare to eclectic reasoning and inductive reasoning. Students develop superiority in abstract reasoning, deductive reasoning and analogical reasoning. Students having high level of reasoning ability in science exhibited higher attitude towards science. The outcomes of this investigation have important implication for education. The implications of the study guide theoretical significance to affective classroom climate, teaching-learning process, curricular programmes, teacher- pupil interaction and on the whole a good general school organizational climate. The importance of analytical and cognition skill for affective functioning in science suggest the need for portray and developing these skills in all students because not only these skills essential for success, but also they form an integral part of one ability to cope with a dynamic, social and cultural environment. Therefore it is important to note high performance in reasoning ability is a prerequisite for success in technological and scientific pursued. Moreover, Abstract reasoning, Analogical reasoning, and Deductive reasoning are found to be reliable predictions of performance in high school science courses. Another implication of the study is to explore the viability of institutional climates to and of graded standard with proper teaching learning conditions and curricular programmes in secondary schools. Better schooling, which is treated as the holistic variable determining cognitive performance, it is important to examine the specific teaching-learning conditions adopted in schools. Therefore studies along these lines are recommended to focus on combining experimental with process oriented investigations to examine which specific cognition processes are associated with improved task performance. The curricular programmes schools therefore may be revisited.

\section{REFERENCES}

[1]. Bell, R.L. \& Lederman, N.G. (2003). Understandings of the nature of science and decision making on science and technology bas ed issues. Science Education, 87, 352-377.

[2]. Cherian, V.I., Kibria, G.F., Kariuki, P.W. and Mwamwenda, T.S.(1988). "Formal Operational Reasoning in African University Students". The Journal of Psychology, 122, (5), 487-498.

[3]. Chickering, A.W. and Gamson, Z.F.(1987). Seven Principles for Good Practice in Undergraduate Education, Washington, DC: American Association for Higher Education, pg- 282

[4]. Curd, M. \& Cover, J.A. (1998). Philosophy of science: The central issues. New York : Norton

[5]. Cloutier, R. and Goldschmid, M.L.(1976). "Individual Differences in the Development of Formal Rerasoning". Child Development, 47, 1097-1102.

[6]. Finegold, M. and Mass, R.(1985). "Differences in the Processes of Sooving Physics Problems Between Good Physics Problem Solvers and Poor Physics Problem Solver”. Research in Science and Technological Education. 3(1), 59-67.

[7]. Fleming, R. (1986). Adolescent reasoning in socio-scientific issues. Part-I : Social cognition. Journal of Research in Science Teaching, 23, 677-687.

[8]. Good, C.V. (1973). "Dictionary of Education" $48^{\text {th }}$ Edition, Newyork, McGraw Hill Book Co. Inc.

[9]. Ghosh, S. (1989). A critical study of scientific attitude and aptitude of the students and determination of some determinants of scientific attitude. Ph.D.,Edu.Univ. of Kalyani.

[10]. Helgeson, S.L.(1992). "Problem Solving Research in Middle/Junior School Science Education," Columbus, OH: ERIC Clearing house for Science, Mathematics and Environmental Education. (pg-351)

[11]. Hernandez, L.D., Marek, E.A., and Renner, J.W.(1984). "Relationships among Gender, Age and Intellecltual Development". Journal of Research in Science Teaching, 1(4) 365-375.

[12]. Joshi, A. and Mahapatra, B.C.(1994).Manual for reasoning ability in science. Agra: National Psychological Corporation.

[13]. Kolsto, S.D.( 2001), Scientific literacy for citizenship : Tools for dealing with the science dimension of controversial socio scientific issues., Science Education, 85, 291-310.

[14]. Kortland, K. (1996). An STS case study about students' decision making on the waste issue. Science Education, 80, 673-689

[15]. Kuhn, D. (1993). Science as argument : Implications for teaching and learning scientific thinking. Science Education, 77, $319-337$.

[16]. Lawson (1982). Formal Reasoning, Achievement and Intelligence : an issue of Importance - "Science Education"' Vol-66(1) 77-83.

[17]. Lawwon, A.E.(1982). "Formal Reasoning, Achievement and Intelligence : an Issue of Importance". Science Education, 66(1) 77-83.

[18]. Lederman, N.G. (1992). Students' and teachers' conceptions of the nature of science : A review of the research. Journal of Research in Science Teaching, 29, 331-359.

[19]. Myers,R.E. and Fouts, J.T.(1992).A Cluster analysis of high school science classroom environments and Attitude Towards Science. Journal of Research In Science Teaching.29.929-937.

[20]. Mohanty, R. (2004). Science education programme in secondary school. New Delhi; Deep and Deep publication Pvt. Limited.

[21]. Simpson,R.D. and Oliver, J.S.(1990).A Summary of the major influence on Attitude Towards Science and Achievement in science among adolescent students. Science Education 75.pg-1-18.

[22]. Sadler, T.D., Chambers, F.W., \& Zeidler, D.L. (2004). Student conceptualizations of the nature of science in response to a socio scientific issue. International Journal of Science Education 26, 387-409.

[23]. Solomon, J. (1994). Knowledge, value and the public choice of science knowledge. In J. Solomon \& G Aikenhead (Eds.) STS education: International perspectives on reform (pp. 99-110) New York : Teachers College Press.

[24]. Stuessy, C.(1984). Correlates of Scientific Reasoning in Adolescents: Experience, Locus of Control, Age, Field DependenceIndependence, Rigidly/Flexibility, IQ, and Gender. Columbus, OH: Doctoral Dissertation. The Ohio State University, (pg- 244 834).

[25]. Stuessy, C.(1984). "Path Analysis : A Model for the Development of Scientific Reasoning Abilities in Adolescents". Journal of Research in Science Teaching, 26(1), 41-53.

[26]. Tweney, T.D. (1991). Informal reasoning in science. In J.F. Voss, D.N. Perkins, \& J.W. Segal (Eds.), viz., Informal reasoning and education (pp. 3-16). Hillsdale, NJ: Erlbaum. 